Case Report

\title{
Magnetic Apposition across the Epiglottis: Radiographic and Operative Correlation of a Rare Hypopharyngeal Foreign Body
}

\author{
Yeli Pi $\mathbb{D},{ }^{1}$ Shilpa Radhakrishnan, ${ }^{1}$ Yaser Alrajhi, ${ }^{2}$ and Ravi Bhargava ${ }^{1}{ }^{1}$ \\ ${ }^{1}$ Department of Radiology and Diagnostic Imaging, University of Alberta, Edmonton, Alberta, Canada \\ ${ }^{2}$ Department of Otolaryngology Head and Neck Surgery, University of Alberta, Edmonton, Alberta, Canada \\ Correspondence should be addressed to Ravi Bhargava; rb4@ualberta.ca
}

Received 20 November 2019; Accepted 30 December 2019; Published 3 February 2020

Academic Editor: Amit Agrawal

Copyright (C) 2020 Yeli Pi et al. This is an open access article distributed under the Creative Commons Attribution License, which permits unrestricted use, distribution, and reproduction in any medium, provided the original work is properly cited.

\begin{abstract}
Background and Aim. Rare-earth magnet ingestions are a subset of foreign body ingestions and can result in significant morbidity secondary to pressure necrosis. These magnets are best visualized radiographically, typically located in the gastrointestinal tract. However, unusual locations of magnetic adherence may include the hypopharynx along the epiglottis, where only 2 previous cases have been reported. Clinicians should be aware of the potential dangers of rare-earth magnet ingestion and consider atypical locations of attachment in the appropriate clinical setting. Case Presentation. We present an interesting case of a fourteen-year-old female patient who presents with witnessed ingestion of multiple rare-earth magnets. Soft-tissue neck radiographs demonstrate two adjacent rounded radiopaque densities in the hypopharynx. Intraoperative images confirmed the radiographic findings and identified two magnetic balls stuck along the dorsal and ventral aspect of the epiglottis without evidence of pressure necrosis. Conclusion. This is the first published case of magnetic foreign body adherence to the epiglottis in the Radiology literature. Awareness and recognition of the unique radiographic findings of this rare entity can help clinicians streamline timely management.
\end{abstract}

\section{Introduction}

Foreign body ingestion/aspiration is a common event in children and adolescents, accounting for over 60,000 cases annually in the United States [1]. While coins, balls, and pearls are some of the more commonly ingested/aspirated items [2], clinicians must maintain a high degree of suspicion for magnets and batteries, due to their potential for serious and even fatal sequelae. A particularly dangerous subset of magnets is small rare-earth magnets such as neodymium magnets, which are substantially stronger than traditional ferrite magnets $[3,4]$. Ingestion of multiple of these "supermagnets" is of special concern, as they can attract through intestinal walls, resulting in pressure necrosis, fistulization, and bowel perforation [5-7].

Numerous cases of rare-earth magnet ingestion have been reported in the literature [4-8]. However, hypopharyngeal magnetic foreign body aspirations are less commonly described.
We present a rare case of epiglottic magnetic foreign bodies in a 14-year-old patient. To our knowledge, this is the third case of magnetic foreign body adherence to the epiglottis in the current literature and the first published case in the Radiology literature.

\section{Case Presentation}

A 14-year-old, immunized, previously healthy female presented to our institution, a large tertiary pediatric center, with the chief complaint of "foreign bodies." As per triage note timed 12:23 hours, the patient described having "swallowed two magnetic balls... [and] thinks they are stuck in the throat." The patient was in no acute distress, and her vitals were stable including a normal blood pressure and 97\% oxygen saturation on room air. She was assigned category 3 on the Canadian Triage and Acuity Score (CTAS), an "Urgent" rating that recommends time to physician evaluation less than 30 minutes [9]. 


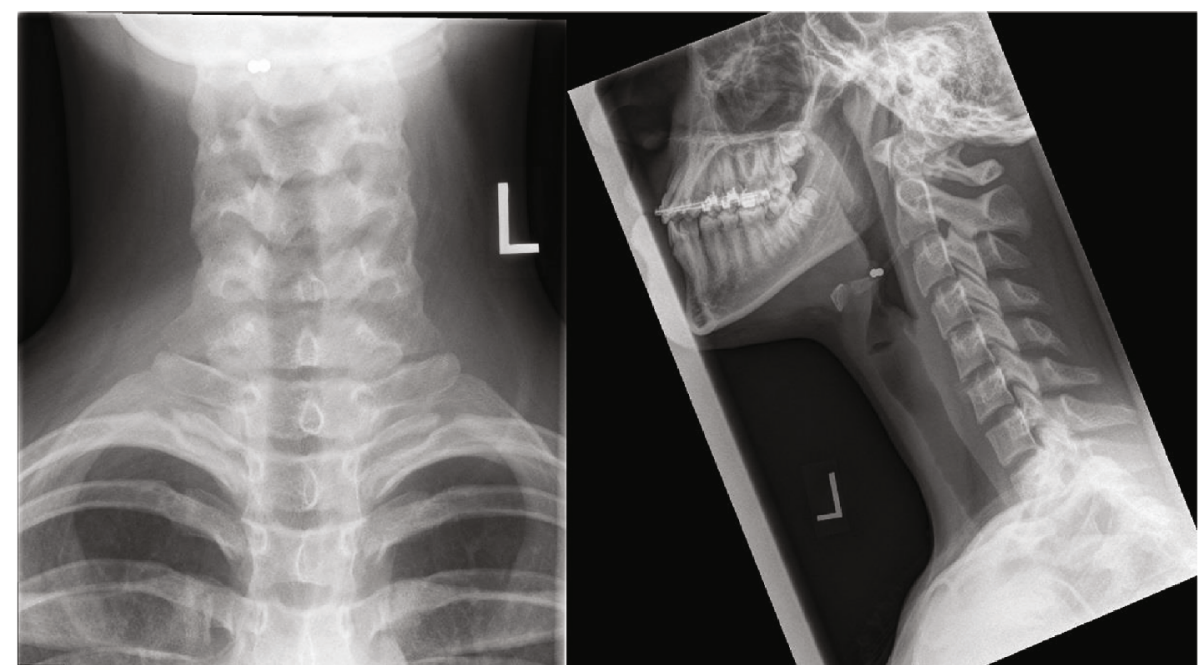

Figure 1: AP and lateral images of the neck demonstrate two adjacent rounded $3 \mathrm{~mm}$ metallic foreign bodies at the C2-3 level eccentric to the right.

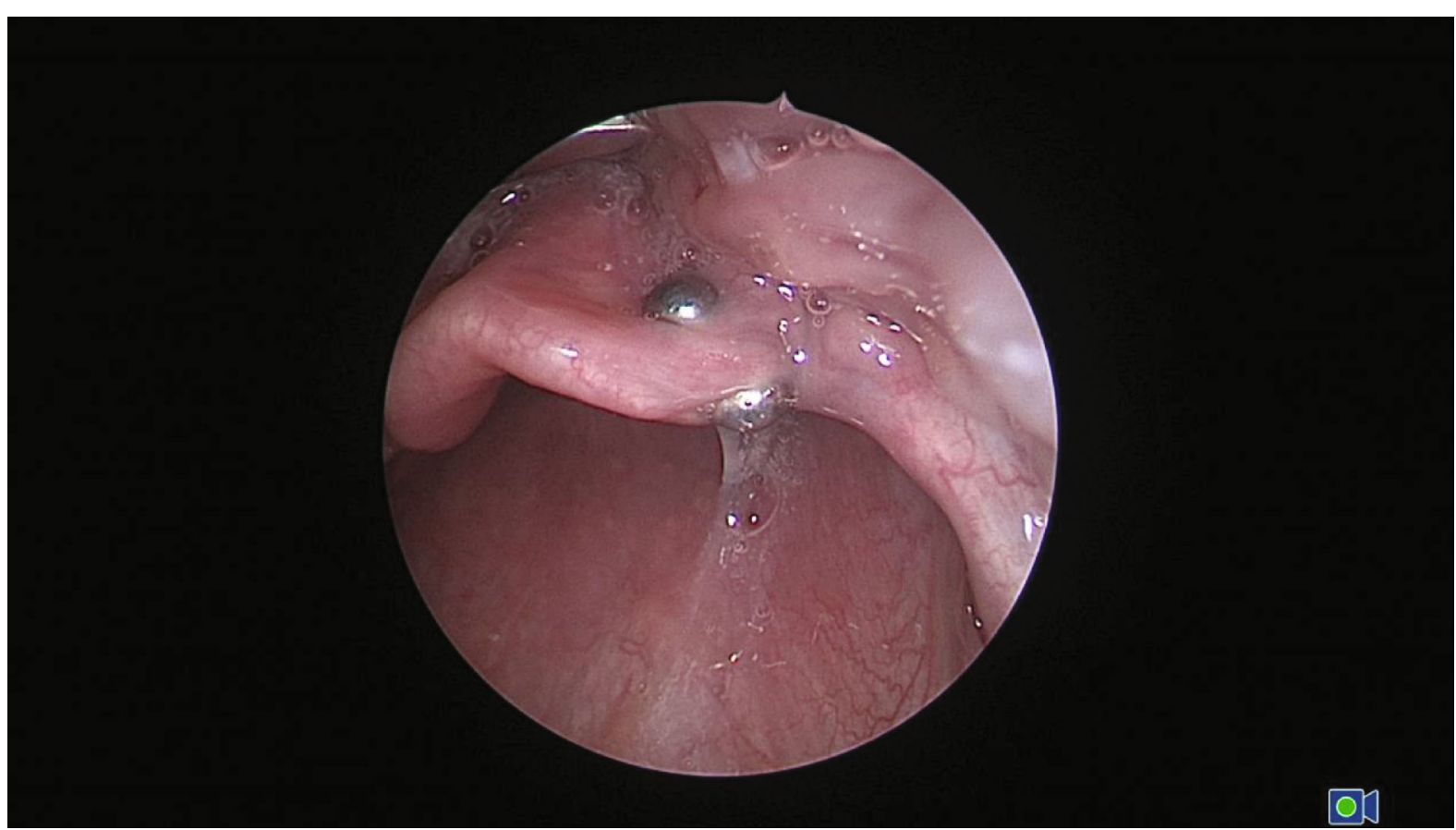

Figure 2: Intraoperative image demonstrates ball magnets along the ventral and dorsal side of the epiglottis, corresponding to radiographic findings.

The patient was assessed by a pediatric emergency physician within an appropriate timeframe and sent for further evaluation. AP and lateral nasopharyngeal radiographs were obtained at 13:17 hours, which demonstrated two adjacent round $3 \mathrm{~mm}$ metallic densities at the C2-3 level, slightly eccentric to the right (Figure 1). The location suggested that the magnets were potentially stuck to the epiglottis. A single additional similar-appearing metallic object was seen in the right lower quadrant on abdominal radiograph (image not shown).

The findings were urgently relayed to the referring clinician, as well as the pediatric otolaryngology service.
Shortly after, the patient was brought to the operating room by 14:23 hours. Under laryngoscopy, two tiny spherical magnets were visualized along the ventral and dorsal surface of the epiglottis eccentrically to the right, corresponding to the radiographic findings (Figure 2). The epiglottis appeared slightly edematous, with no obvious evidence of pressure necrosis. The magnets were retrieved simultaneously via forceps. The patient was stable throughout the entire procedure and was discharged home after two hours of postprocedural monitoring. The single gastrointestinal magnet was treated conservatively and allowed to pass with bowel movements. 


\section{Discussion}

Foreign body aspiration/ingestion events may present with a wide variety of symptoms ranging from completely asymptomatic to gagging, coughing, vomiting, or severe respiratory distress [10-13]. Thus, a chief complaint of magnetic foreign body ingestion/aspiration should be triaged as high acuity, for instance a CTAS category 2 (Emergent; time to physician assessment less than 15 minutes) or even CTAS category 1 (Resuscitative; immediate physician assessment) in the appropriate clinical setting [9]. This history should also trigger a detailed investigation including a thorough history, physical examination, and imaging.

As prior studies have indicated, the primary means for investigating suspected foreign body is conventional radiography, including views of the neck, chest, and abdomen $[11,14,15]$. It is crucial for clinicians and radiologists to complete the radiographic evaluation, as the absence of a foreign body at one location does not exclude upstream or downstream culprits. Conversely, if a foreign object is identified (such as in our patient), we still encourage completing additional imaging to avoid the satisfaction of search and prevent undue morbidity due to delayed diagnosis. Crosssectional imaging may be considered as the next step of investigation, especially if there is strong clinical concern for a nonradiopaque foreign body $[16,17]$.

On conventional radiographs, rounded or ovoid radiopaque densities, particularly in a linear or stacked configuration, should quickly raise concern for multiple magnets. Antidependent or atypical locations may also be a clue of nonmobile magnets attracted to one another.

In our case, both of these factors were evident and allowed for timely diagnosis and management. Nearly identical imaging features were shown by Brown et al. and Solis et al. in the two other reported cases of epiglottic magnetic foreign bodies [18, 19], suggesting that although unusual, the radiographic findings are essentially pathognomonic for adherent magnets at this location.

Mucosal injury and pressure necrosis of the epiglottis from magnetic attraction could occur relatively rapidly (possibly as soon as 13 hours postingestion), as demonstrated in the previous case reports $[18,19]$. As such, clinicians must operate under the premise that "time is tissue." We recommend prompt communication of this critical result to the most responsible physician, as well as liaison with the pediatric otolaryngology team to streamline potential intervention.

Due to their risk for serious injury, there has been multiple recalls issued by the United States Consumer Product Safety Commission (CPSC) for some of the once-popular neodymium magnet toys, such as Buckyballs and Magtastik [20-22]. The CPSC also issued a Safety Standard for Magnet Sets in 2012, with limits on the size and flux of small rare-earth magnets [23]. However, after multiple appeals and hearings, mandatory recall for products such as Zen Magnets have been recently reversed in 2018, and the incidence of magnetic foreign body ingestions may see an upward trend [24].

\section{Conclusion}

Rare-earth magnet apposition across the epiglottis is an unusual event but its imaging findings are unique, allowing for expedited diagnosis and management. A child presenting with a history of magnetic foreign body ingestion should be prompted triaged and investigated via clinical and imaging means. Early recognition of these spherical metallic bodies is essential for optimizing patient outcomes and preventing pressure necrosis.

\section{Conflicts of Interest}

The authors declare there is no conflict of interest.

\section{References}

[1] D. D. Gummin, J. B. Mowry, D. A. Spyker, D. E. Brooks, K. M. Osterthaler, and W. Banner, "2017 annual report of the American Association of Poison Control Centers' National Poison Data System (NPDS): 35th annual report," Clinical Toxicology, vol. 56, no. 12, pp. 1213-1415, 2018.

[2] D. Passali, D. Gregori, G. Lorenzoni et al., "Foreign body injuries in children : a review," Acta Otorhinolaryngologica Italica, vol. 35, no. 4, pp. 265-271, 2015.

[3] D. Orsagh-Yentis, R. J. Mcadams, K. J. Roberts, and L. B. Mckenzie, "Foreign-body ingestions of young children treated in US emergency departments: 1995-2015," Pediatrics, vol. 143, no. 5, article e20181988, 2019.

[4] S. McCormick, P. Brennan, J. Yassa, and R. Shawis, "Children and mini-magnets: an almost fatal attraction," Emergency Medicine Journal, vol. 19, no. 1, pp. 71-73, 2002.

[5] M. J. Alfonzo and C. R. Baum, "Magnetic foreign body ingestions," Pediatric Emergency Care, vol. 32, no. 10, pp. 698702, 2016

[6] R. Sola Jr., E. H. Rosenfeld, Y. R. Yu, S. D. St Peter, and S. R. Shah, "Magnet foreign body ingestion: rare occurrence but big consequences," Journal of Pediatric Surgery, vol. 53, no. 9, pp. 1815-1819, 2018.

[7] A. C. de Roo, M. C. Thompson, T. Chounthirath et al., "Rareearth magnet ingestion-related injuries among children, 20002012," Clinical Pediatrics, vol. 52, no. 11, pp. 1006-1013, 2013.

[8] R. E. Kramer, D. G. Lerner, T. Lin et al., "Management of ingested foreign bodies in children: a clinical report of the NASPGHAN endoscopy committee," Journal of Pediatric Gastroenterology and Nutrition, vol. 60, no. 4, pp. 562-574, 2015.

[9] R. Beveridge, B. Clarke, L. Janes et al., "Implementation Guidelines for the Canadian Emergency Department Triage \& Acuity Scale (CTAS)," 1998, December 2019, http://ctas-phctas.ca/ wp-content/uploads/2018/05/ctased16_98.pdf.

[10] F. Foltran, S. Ballali, F. M. Passali et al., "Foreign bodies in the airways: a meta-analysis of published papers," International Journal of Pediatric Otorhinolaryngology, vol. 76, pp. S12S19, 2012.

[11] E. Lea, H. Nawaf, T. Yoav, S. Elvin, Z. Ze'ev, and K. Amir, "Diagnostic evaluation of foreign body aspiration in children: a prospective study," Journal of Pediatric Surgery, vol. 40, no. 7, pp. 1122-1127, 2005.

[12] S. Jayachandra and G. D. Eslick, "A systematic review of paediatric foreign body ingestion: presentation, complications, 
and management," International Journal of Pediatric Otorhinolaryngology, vol. 77, no. 3, pp. 311-317, 2013.

[13] A. Boufersaoui, L. Smati, K. N. Benhalla et al., "Foreign body aspiration in children: experience from 2624 patients," International Journal of Pediatric Otorhinolaryngology, vol. 77, no. 10, pp. 1683-1688, 2013.

[14] B. S. Pugmire, R. Lim, and L. L. Avery, "Review of ingested and aspirated foreign bodies in children and their clinical significance for radiologists," RadioGraphics, vol. 35, no. 5, pp. 1528-1538, 2015.

[15] M. Kay and R. Wyllie, "Pediatric foreign bodies and their management," Current Gastroenterology Reports, vol. 7, no. 3, pp. 212-218, 2005.

[16] S. J. Hong, H. W. Goo, and J. L. Roh, "Utility of spiral and cine CT scans in pediatric patients suspected of aspirating radiolucent foreign bodies," Otolaryngology-Head and Neck Surgery, vol. 138, no. 5, pp. 576-580, 2008.

[17] H. J. Tseng, T. N. Hanna, W. Shuaib, M. Aized, F. Khosa, and K. F. Linnau, "Imaging foreign bodies: ingested, aspirated, and inserted," Annals of Emergency Medicine, vol. 66, no. 6, pp. 570-582.e5, 2015.

[18] J. C. Brown, F. M. Baik, H. C. Ou, J. P. Otjen, H. G. Parish, and D. K. Chan, "Upper aerodigestive magnetic foreign bodies in children," The Laryngoscope, vol. 124, no. 6, pp. 1481-1485, 2014.

[19] R. N. Solis, F. Lenes-voit, R. B. Mitchell, and G. Shah, "Rare earth metal magnets: an unusual airway foreign body," Ear, Nose \& Throat Journal, 2019.

[20] US Consumer Product Safety Commission, "Buckyballs and Buckycubes high-powered magnet sets recalled due to ingestion hazard; Craig Zucker to fund a recall trust, settles with CPSC," 2014, December 2019, https://www.cpsc.gov/content/ buckyballs-and-buckycubes-high-powered-magnet-setsrecalled.

[21] US Consumer Product Safety Commission, "MEGA brands recalls Magtastik and Magnetix Jr. Pre-school magnetic toys; ingested magnets pose aspiration and intestinal hazards," 2008, December 2019, https://www.cpsc.gov/Recalls/2008/ MEGA-Brands-Recalls-Magtastik-and-Magnetix-Jr-PreSchool-Magnetic-Toys-Ingested-Magnets-Pose-Aspirationand-Intestinal-Hazards.

[22] Consumer Report News, "CPSC recalls 4 million Magnetix toys; issues warning on magnets," 2007, December 2019, https://www.consumerreports.org/cro/news/2007/04/cpscrecalls-4-million-magnetix-toys-issues-warning-on-magnets/ index.htm\#.

[23] US Consumer Product Safety Commission, "Safety standard for magnet sets," Federal Register, vol. 77, no. 171, pp. 53781-53801, 2012.

[24] "Zen Magnets LLC v. United States of America Consumer Product Safety Commission,” 2018, https://casetext.com/ case/zen-magnets-llc-v-us-consumer-prod-safety-commn. 